\title{
The Role of Eddies in the Southern Ocean Temperature Response to the Southern Annular Mode
}

\author{
James A. ScReen and Nathan P. Gillett \\ Climatic Research Unit, School of Environmental Sciences, University of East Anglia, \\ Norwich, United Kingdom \\ DAVID P. STEVENS \\ School of Mathematics, University of East Anglia, Norwich, United Kingdom \\ GARETH J. MARShall AND Howard K. Roscoe \\ British Antarctic Survey, Cambridge, United Kingdom
}

(Manuscript received 8 January 2008, in final form 1 August 2008)

\begin{abstract}
The role of eddies in modulating the Southern Ocean response to the southern annular mode (SAM) is examined, using an ocean model run at multiple resolutions from coarse to eddy resolving. The high-resolution versions of the model show an increase in eddy kinetic energy that peaks $2-3$ yr after a positive anomaly in the SAM index. Previous work has shown that the instantaneous temperature response to the SAM is characterized by predominant cooling south of $45^{\circ} \mathrm{S}$ and warming to the north. At all resolutions the model captures this temperature response. This response is also evident in the coarse-resolution implementation of the model with no eddy mixing parameterization, showing that eddies do not play an important role in the instantaneous response. On the longer time scales, an intensification of the mesoscale eddy field occurs, which causes enhanced poleward heat flux and drives warming south of the oceanic Polar Front. This warming is of greater magnitude and occurs for a longer period than the initial cooling response. The results demonstrate that this warming is surface intensified and strongest in the mixed layer. Non-eddy-resolving models are unable to capture the delayed eddy-driven temperature response to the SAM. The authors therefore question the ability of coarse-resolution models, such as those commonly used in climate simulations, to accurately represent the full impacts of the SAM on the Southern Ocean.
\end{abstract}

\section{Introduction}

The southern annular mode (SAM) is the dominant mode of extratropical atmospheric variability in the Southern Hemisphere (Thompson and Wallace 2000; Marshall et al. 2004). Southern Ocean sea surface temperatures (SSTs) respond to the SAM through a combination of modified surface currents and atmosphereocean heat fluxes (Hall and Visbeck 2002; Verdy et al. 2006; Sen Gupta and England 2006; Ciasto and Thompson 2008). During the positive phase of the

Corresponding author address: James Screen, Climatic Research Unit, School of Environmental Sciences, University of East Anglia, Norwich, NR4 7TJ, United Kingdom.

E-mail: j.screen@uea.ac.uk
SAM, stronger westerlies between $50^{\circ}$ and $70^{\circ} \mathrm{S}$ enhance the northward Ekman transport of cold water contributing to cold SST anomalies at these latitudes. Further north, between $25^{\circ}$ and $45^{\circ} \mathrm{S}$, easterly wind anomalies drive the anomalous southward Ekman transport of warm water, contributing to warm SST anomalies at these latitudes. In addition, the SAM induces atmosphere-ocean heat flux anomalies that play an important role in determining the SST response. Although not as zonal as the Ekman anomalies, a positive anomaly in the SAM is largely associated with negative surface heat flux anomalies centered at $60^{\circ} \mathrm{S}$ and positive surface heat flux anomalies centered at $40^{\circ} \mathrm{S}$ (Sen Gupta and England 2006).

One of the most important recent climatic trends in the Southern Hemisphere has been a strengthening and poleward contraction of the circumpolar westerlies over 
the Southern Ocean. This corresponds to a shift of the SAM index toward an increasingly positive phase. Evidence suggests that the trend is largely human induced (Thompson and Solomon 2002; Gillett and Thompson 2003; Marshall et al. 2004; Arblaster and Meehl 2006; Roscoe and Haigh 2007). Over the same time period there has been pronounced warming of the Southern Ocean. Gille (2002) demonstrates a warming at depths of 700-1100 m since the 1950s, with further investigations suggesting that this warming extends to the nearsurface layers with undiminished magnitude (Gille 2008). Regional studies also support the idea that the Southern Ocean has warmed over recent decades (Aoki et al. 2003; Alory et al. 2007). The cause of this observed warming is still a matter of debate. It has been argued that it could be as a result of a poleward shift in the Antarctic Circumpolar Current (ACC) (Oke and England 2004; Fyfe et al. 2007; Gille 2008), a southward intensification of the subtropical gyres (Cai 2006; Alory et al. 2007), or as a consequence of enhanced eddy heat flux (Meredith and Hogg 2006; Hogg et al. 2008). It is likely that a combination of these mechanisms have contributed to the observed temperature trends (Fyfe et al. 2007); however, it is the eddy field response to the SAM and the subsequent effects on Southern Ocean temperatures that we explore here.

Eddies are responsible for a poleward heat flux and play a role in the time-varying heat budget of the Southern Ocean (de Szoeke and Levine 1981; Lee et al. 2007). Fyfe et al. (2007) adapt the parameterization scheme of a coarse-resolution $\left(3.6^{\circ} \times 1.8^{\circ}\right)$ climate model to include an increase in eddy isopycnal thickness diffusivity, in proportion to an increase in wind stress. They demonstrate that enhanced mesoscale eddy activity, following an increase in the wind stress, increases the poleward heat transport. However, their relatively coarse-resolution model is unable to directly resolve the effects of eddies. Hallberg and Gnanadesikan (2006) find significant differences in the response of the Southern Ocean to wind stress changes between eddy-resolving and non-eddy-resolving versions of a primitive-equation isopycnal coordinate model. These authors question the ability of coarse-resolution climate models to accurately capture changes in the wind-driven circulation. In an eddy-resolving quasigeostrophic model, Meredith and Hogg (2006) show that eddy kinetic energy (EKE) increases 2-3 yr after a positive peak in the SAM index. They attribute this increase to enhanced circumpolar wind stress and demonstrate that the lag is due to the time taken to influence the circulation in the deep ocean. Hogg et al. (2008) further demonstrate that SSTs south of the ACC increase in response to this intensification of the eddy field.
The goal of this study is to provide a greater understanding of the role of eddies in contributing to the ocean temperature response to the SAM. The study tests previously published findings but also extends earlier work by 1) using an eddy-resolving primitive-equation global ocean model forced with time-varying surface momentum, heat, and freshwater fluxes constrained by observations; 2) looking at the temperature response from the surface to the middepth ocean; and 3) assessing the ability of coarse-resolution models, in which oceanic mesoscale eddies are parameterized, to represent the eddy-driven temperature response to the SAM.

\section{Data and methods}

Results are presented from the Ocean Circulation and Climate Advanced Model (OCCAM), which is run at three horizontal resolutions $-1^{\circ}, 1 / 4^{\circ}$, and $1 / 12^{\circ}$-from coarse to eddy resolving. Comparing different resolutions provides an indication of the impact of explicitly resolved mesoscale eddies. OCCAM is a primitiveequation numerical model of the global ocean (Coward and de Cuevas 2005). All horizontal resolutions of the model have 66 vertical levels, varying in thickness from $5 \mathrm{~m}$ at the surface to $208 \mathrm{~m}$ at a depth of $6370 \mathrm{~m}$. The thickness of the bottom layer in each column is adjusted to give a better fit to topography. A grid box centered at $60^{\circ} \mathrm{S}$ has an approximate size of $55 \mathrm{~km} \times 110 \mathrm{~km}$ at $1^{\circ}$ resolution, reducing to $4.5 \mathrm{~km} \times 9 \mathrm{~km}$ at $1 / 12^{\circ}$ resolution. Mesoscale eddies have a length scale that varies from approximately $200 \mathrm{~km}$ at low latitudes to $10 \mathrm{~km}$ at the latitudes of the Drake Passage (Chelton et al. 1998). In the $1^{\circ}$ model, eddies are parameterized using the scheme proposed by Gent and McWilliams (1990). This is typical of state-of-the-art climate models. The $1 / 4^{\circ}$ model includes the same eddy parameterization scheme; however, some larger eddies are explicitly resolved. The Gent-McWilliams (GM) diffusivities are horizontally and vertically constant with a value of $50 \mathrm{~m}^{2} \mathrm{~s}^{-1}$ in the $1 / 4^{\circ}$ model and $600 \mathrm{~m}^{2} \mathrm{~s}^{-1}$ in the $1^{\circ}$ model. The $1 / 12^{\circ}$ model has no associated parameterization scheme and eddies are explicitly resolved. We also present output from an additional run of the $1^{\circ}$ model with no eddy parameterization scheme (hereafter the no-GM run). In this model configuration, mesoscale eddies are neither resolved nor parameterized (although there is still harmonic isopycnal diffusion), and consequently the effects of eddies are unaccounted for.

In all resolutions of the model, the initial tracer fields were interpolated from the World Ocean Circulation Experiment climatological values (Gouretski and Jancke 1996) and the initial velocities were set to zero. The models 
were then forced with surface momentum, heat, and freshwater fluxes calculated from the bulk formulas using 6-hourly atmospheric fields from the National Centers for Environmental Prediction-National Center for Atmospheric Research (NCEP-NCAR) reanalysis for the 20-yr period from 1985 to 2004 (Kalnay et al. 1996; Large et al. 1997). The first $3 \mathrm{yr}$ of OCCAM output have been discarded to remove the period of initial model spinup. Preliminary analyses suggested that the models (particularly the $1^{\circ}$ and no-GM runs) had not reached a steady state at the end of the spinup period. To circumvent this issue the linear trends have been subtracted from all time series to remove the effects of linear model drift. To test for possible effects of nonlinear drift, the $1^{\circ}$ model was run for $60 \mathrm{yr}$ using three successive cycles of the 20 -yr forcing fields. The results from later cycles were consistent with those from the first cycle showing that nonlinear model drift is not a major concern. Accordingly, only the results from the first cycle are presented in the following sections. The linear component of the drift was substantially less in the higher-resolution runs than the $1^{\circ}$ runs, and therefore we assume that the nonlinear component of the drift is no more important in the higher-resolution models than in the low-resolution model.

The EKE was defined as

$$
\mathrm{EKE}=\frac{1}{2} \overline{u^{\prime 2}+v^{\prime 2}}
$$

where $u^{\prime}$ and $v^{\prime}$ are the eastward and northward velocity anomalies and the overbar represents a time average. In the $1 / 12^{\circ}$ and $1 / 4^{\circ}$ models, annual mean EKE was derived from a sequence of 5-day mean velocities with the long-term $(73 \times 5$ day $)$ means removed. We have chosen to use velocities at 8-m depth (model level 2) rather than the surface level to reduce contamination by ageostrophic Ekman transport. In the $1^{\circ}$ model, eddies are not explicitly resolved, thus the EKE was not calculated. Observational estimates of EKE were calculated from surface geostrophic current anomalies derived from the Ocean Topography Experiment (TOPEX)/Poseidon (T/P) and Jason satellite altimeter data. These data were obtained on a $1 / 3^{\circ}$ Mercator grid at 7-day intervals covering the 1993-2006 period. We have used data solely from the T/P and Jason (which succeeded T/P and follows the same orbit) satellites rather than using the merged multisatellite product. Previous authors have found anomalously low EKE during 1994 in the merged product, which corresponds to a period when data from the European Remote Sensing Satellite (ERS) were not assimilated (Ducet et al. 2000).

SST observations were taken from the Hadley Centre Global Sea Ice and Sea Surface Temperature (HadISST) dataset (Rayner et al. 2003). HadISST comprises monthly global fields on a $1^{\circ}$ latitude-longitude grid. The dataset is derived from quality-controlled in situ measurements and satellite estimates. The SAM index was calculated by projecting monthly $850-\mathrm{hPa}$ geopotential height anomalies from the NCEP-NCAR reanalysis onto the leading EOF south of $20^{\circ} \mathrm{S}$. The NCEP-NCAR reanalysis was used because the atmospheric forcing fields for OCCAM are based on this reanalysis. The SAM index was normalized by its standard deviation during the 20-yr OCCAM period (19852004). To enable us to examine lagged relationships we used values of the SAM index for the 1982-2006 period.

Annual means were used throughout. All time series were detrended and the long-term mean removed before calculating the regression coefficients. The regression coefficients were tested for statistical significance using a standard two-tailed $t$ test in which the effective sample size $N_{\text {eff }}$ is estimated as

$$
N_{\text {eff }}=N\left[\frac{1-r_{1} r_{2}}{1+r_{1} r_{2}}\right]
$$

where $N$ is the sample size and $r_{1}$ and $r_{2}$ are the lag-one autocorrelations of the two time series being regressed (Bretherton et al. 1999). Where we have performed lagged regressions the oceanic variable is lagging the SAM; hence, we were testing for changes in the SAM driving changes in the Southern Ocean and not vice versa.

\section{Eddy kinetic energy in the Southern Ocean}

The spatial patterns of long-term mean EKE in the $1 / 12^{\circ}$ and $1 / 4^{\circ}$ versions of the OCCAM model and from satellite altimetry are shown in Fig. 1. The location of the oceanic Polar Front (PF) has been calculated using the methodology of Belkin and Gordon (1996). The front is defined as the northern extent of the subsurface minimum temperature layer bounded by the $2^{\circ} \mathrm{C}$ isotherm at $100-300-m$ depth. The mean PF location is insensitive to model resolution, so for simplicity we consistently plot the mean path in the $1 / 12^{\circ}$ version of the model. The most energetic regions are found in the vicinity of the ACC, the Agulhas Current, the BrazilMalvinas Current confluence, and the East Australian Current separation. It has long been known that these regions of the Southern Ocean are characterized by high eddy energy (Wilkin and Morrow 1994). In particular, high EKE is seen within a band located at approximately $40^{\circ} \mathrm{S}$ stretching from south of Africa into the Indian Ocean. The spatial pattern and magnitude of mean EKE in the $1 / 12^{\circ}$ model show good agreement 

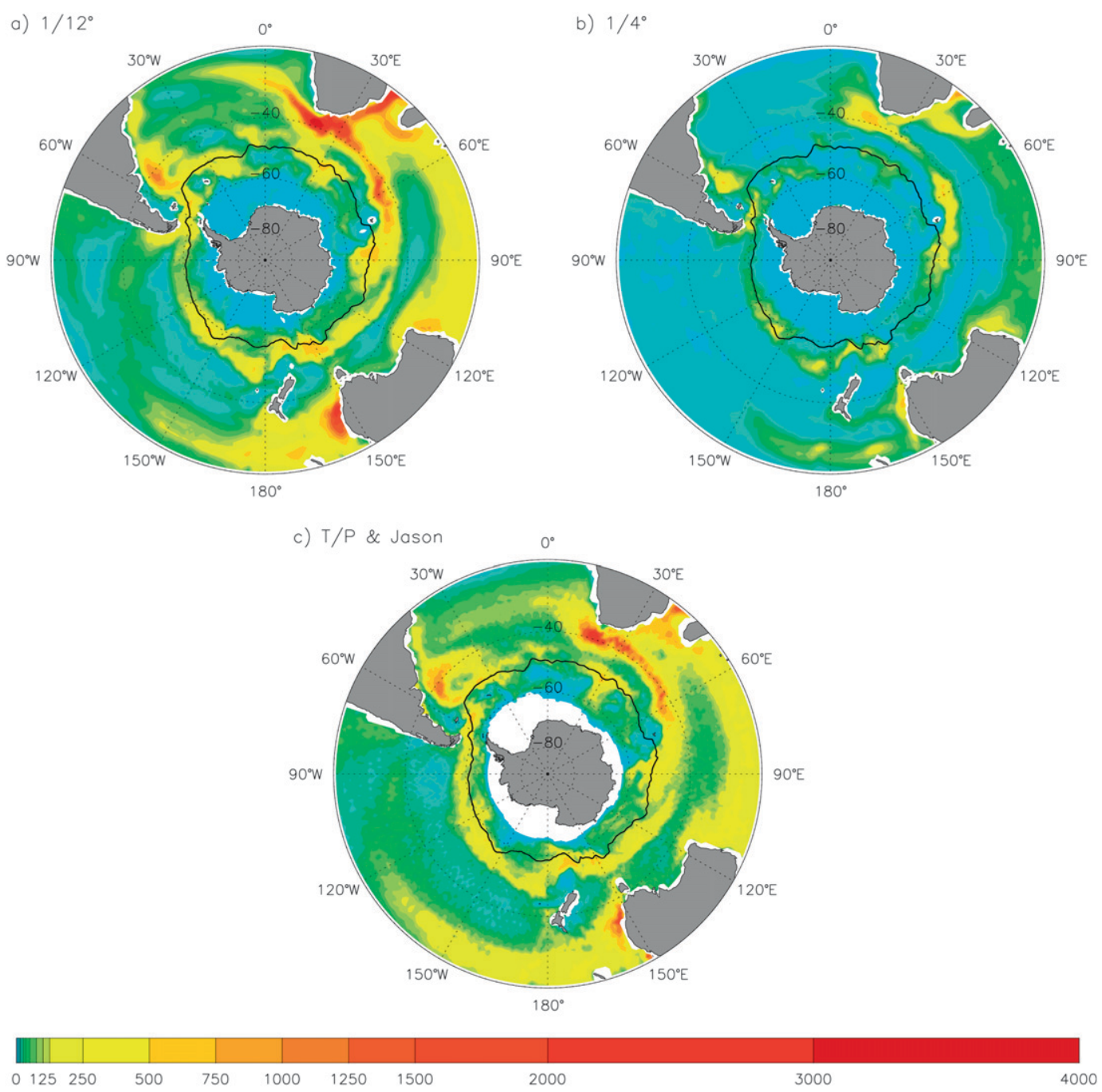

FIG. 1. Mean EKE in the (a) $1 / 12^{\circ}$ and (b) $1 / 4^{\circ}$ resolution versions of the OCCAM model and (c) satellite altimetry. All values are in $\left(\mathrm{cm} \mathrm{s}^{-1}\right)^{2}$. All plots have been regrided to $1^{\circ}$ resolution for direct comparison. Also shown is the mean location of the Polar Front (black line).

with that from satellite altimetry. The spatial pattern of mean EKE in the $1 / 4^{\circ}$ model is in good agreement with observations, however, it is clear that this model version consistently underestimates the EKE. At almost all locations the EKE is higher in the $1 / 12^{\circ}$ model than the $1 / 4^{\circ}$ model, and features such as the Agulhas retroflection are better resolved at higher resolution. It is worth noting that the weak EKE in the $1 / 4^{\circ}$ model may in part be caused by the parameterization scheme. An increase in wind stress will act to steepen the isopycnal slope across the ACC. In the $1 / 4^{\circ}$ model, the parameterization scheme competes with explicit eddies to flatten the isopycnal slopes. As a consequence some of the potential energy will be drained by the parameterization scheme rather than being converted to kinetic energy through baroclinic instability. It is likely that the $1 / 4^{\circ}$ model would show higher EKE in the absence of the parameterization scheme.

We now examine whether the models show any delayed intensification of the mesoscale eddy field in response to the SAM, as proposed by Meredith and Hogg (2006). Figure 2 shows the lagged response of annual mean EKE (averaged between $35^{\circ}$ and $65^{\circ} \mathrm{S}$ ) to a positive anomaly in the SAM. In both the $1 / 12^{\circ}$ and $1 / 4^{\circ}$ models and in the satellite estimates, EKE increases following a positive SAM event with the EKE maximum lagging the SAM by approximately $2-3$ yr. Positive regressions are evident at a lag of $2 \mathrm{yr}$, which are statistically significant at better than the 0.1 level in both resolutions of the model [two-tailed probability $(p)$, $\left.1 / 12^{\circ}: p=0.030 ; 1 / 4^{\circ}: p=0.001\right]$. In the satellite data, the EKE increase is statistically significant at a lag of 3 


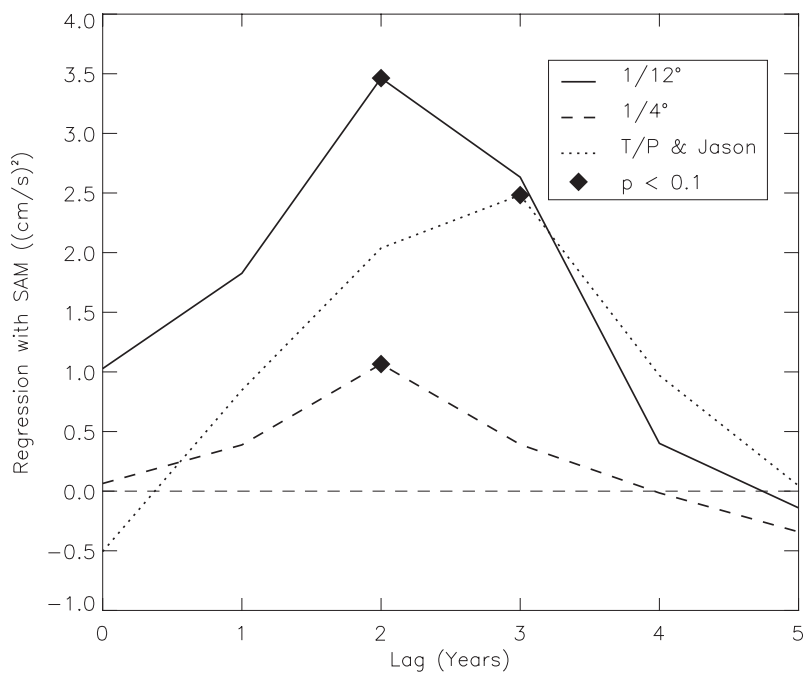

FIG. 2. Lagged regressions between annual mean EKE anomalies and the SAM index in the $1 / 12^{\circ}$ and $1 / 4^{\circ}$ resolution versions of the OCCAM model and from satellite altimetry. EKE anomalies have first been weighted by the cosine of latitude and then averaged over the entire ocean between $35^{\circ}$ and $65^{\circ} \mathrm{S}$. Regressions significant at the 0.1 level or better are shown with diamonds.

yr $(p=0.069)$. The maximum EKE response occurs slightly faster in the models than in the satellite data. However, this difference probably results from the satellite estimates covering a shorter and different time period than that of the OCCAM models rather than from model inaccuracies. During the overlapping period both the models and the satellite data show the maximum EKE response to the SAM at a lag of $2 \mathrm{yr}$ (not shown). The results clearly indicate that a positive anomaly in the SAM index causes an intensification of the Southern Ocean eddy field 2-3 yr after the initial atmospheric disturbance, consistent with the mechanism proposed by Meredith and Hogg (2006). Despite being a feature in both models, the EKE increase at 2-yr lag is approximately 4 times greater in the $1 / 12^{\circ}$ model than in the $1 / 4^{\circ}$ model. The EKE increase in the $1 / 12^{\circ}$ model is also greater than the increase seen in the satellite estimates. This may result from an underestimation of EKE by the satellites, arising because the ground track separation is larger than some mesoscale eddies. Ducet et al. (2000) show that EKE is approximately $30 \%$ greater in merged multisatellite data (which have improved spatial resolution) than in the $\mathrm{T} / \mathrm{P}$ data alone.

\section{Sea surface temperature response to the SAM}

We now turn our attention to the role of eddies in the SST response to the SAM. Figure 3 shows annual mean SSTs regressed against the SAM index for each of the three model resolutions, for the no-GM run and for the observations. The observed instantaneous SST response to the SAM (Fig. 3e) is well represented by all versions of the model. The $1 / 12^{\circ}$ run displays considerable smallscale variability, particularly in a region stretching from $10^{\circ}$ to $80^{\circ} \mathrm{E}$ at approximately $40^{\circ} \mathrm{S}$ (Fig. 3a). This region is likely to have a high degree of SST variability because it coincides with an area of high mesoscale eddy activity (previously identified in Fig. 1). This high SST variability shows up in the $1 / 12^{\circ}$ resolution model SST regression pattern but is not captured by the lowerresolution runs. Note that this difference is not a consequence of the figure resolution because the $1 / 12^{\circ}$ and $1 / 4^{\circ}$ plots have been regridded to $1^{\circ}$ resolution to be consistent with the $1^{\circ}$ OCCAM and HadISST maps. The spatial pattern of this small-scale variability is different at varying lags (Fig. 4), and thus it is likely caused by transient eddies.

The no-GM run also represents the observed SSTSAM regression pattern well, suggesting that eddies do not play an important role in the short-term SST response to the SAM (Fig. 3). This is no surprise because it is well established that the short-term SST response to the SAM is driven by a combination of modified atmosphere-ocean heat fluxes and enhanced Ekman transport (Hall and Visbeck 2002; Sen Gupta and England 2006; Verdy et al. 2006; Ciasto and Thompson 2008). These processes are unlikely to be influenced by the presence of eddies. Furthermore, Fig. 2 shows that the maximum response of the eddy field lags the SAM and therefore the possible effects of eddies on the SSTSAM relationship would not be expected until 2-3 yr after the SAM event.

\section{Eddy-driven changes in sea surface temperatures}

We utilize lagged regressions to discern the delayed temperature response to the SAM. An initial analysis showed that all of the models exhibit common features in the SST-lagged regressions, but these appear to arise from common wind stress and heat flux forcing in the models and contain considerable noise resulting from the short length of the runs. However, differences in the lagged SST regressions existed between the models, which may be related to eddy processes. In the subsequent analyses we use the no-GM run as an estimate of the eddy-independent temperature variability. As shown in Fig. 3, the no-GM run captures the immediate SST response to the SAM induced by surface heat flux and Ekman heat advection anomalies. SST differences ( $\delta$ SSTs) have been calculated by subtracting the temperature anomalies in the no-GM run from the corresponding temperature anomalies in the $1 / 12^{\circ}, 1 / 4^{\circ}$, and $1^{\circ}$ runs. As a consequence, the components of the 
a) $1 / 12^{\circ}$

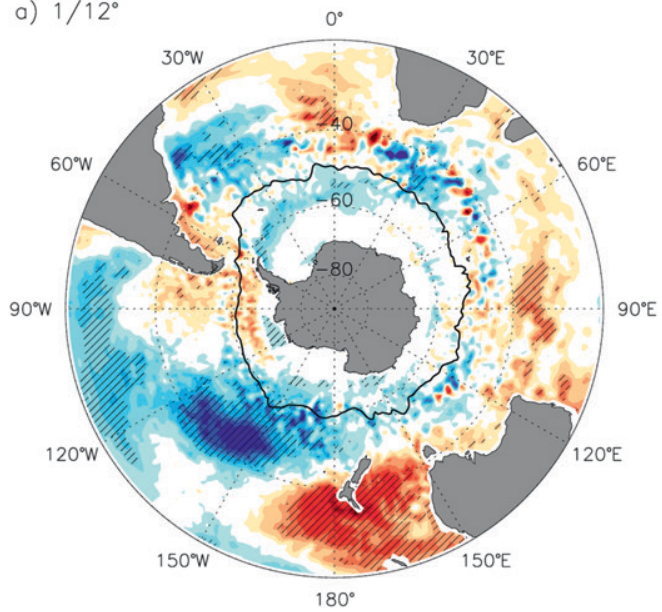

c) $1^{\circ}$

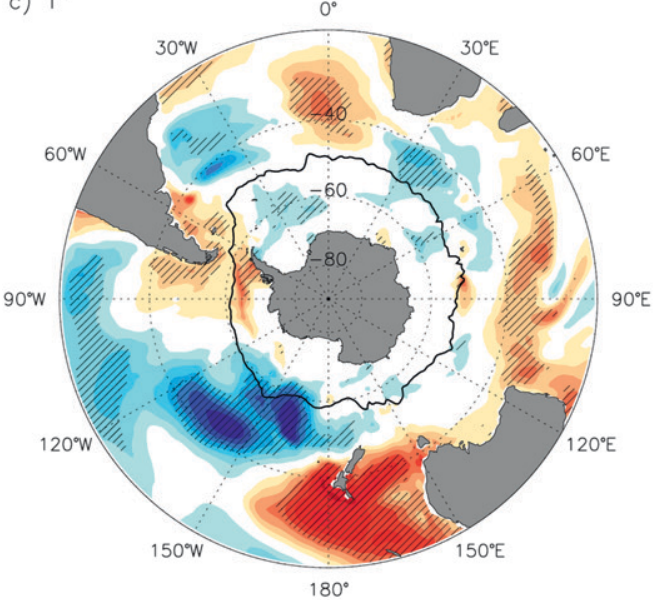

b) $1 / 4^{\circ}$

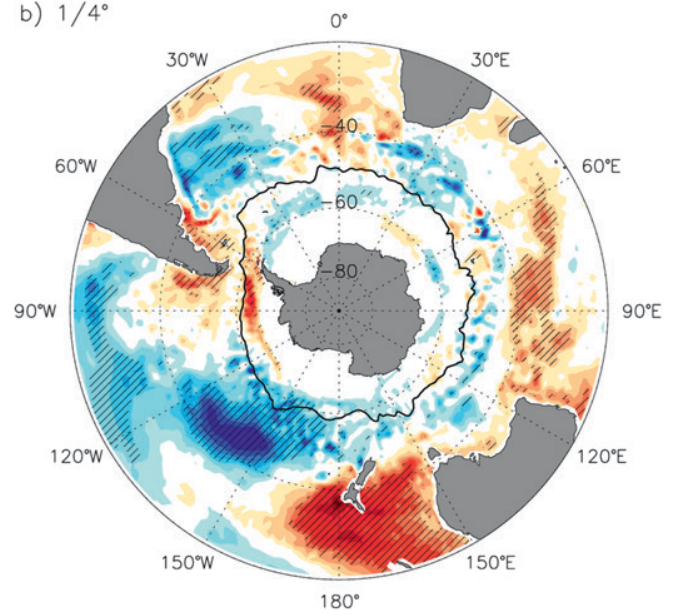

d) no GM

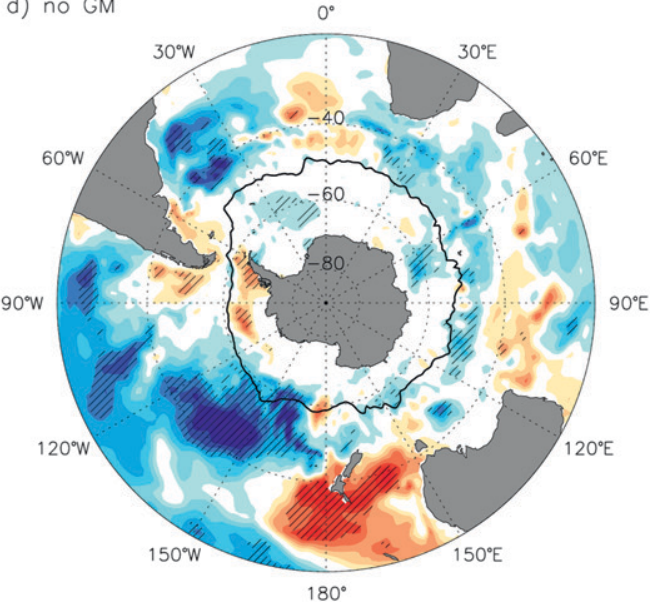

e) HadISST
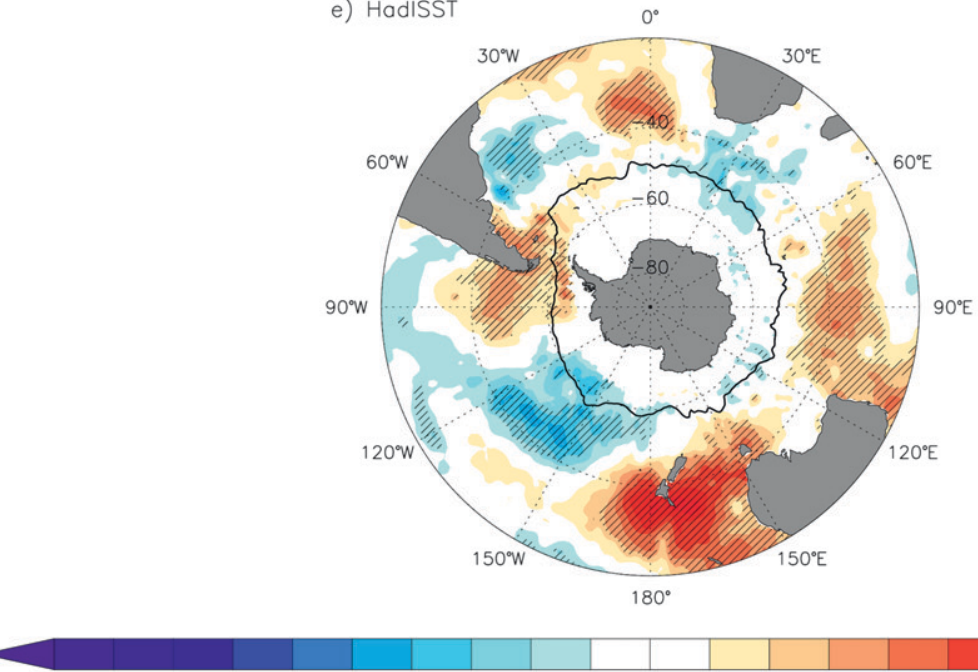

$$
\begin{array}{lllllllllll}
-1.0 & -0.9 & -0.8 & -0.7 & -0.6 & -0.5 & -0.4 & -0.3 & -0.2 & -0.1 & 0.0
\end{array}
$$

FIG. 3. Annual mean SST anomalies regressed against the SAM index using the (a) $1 / 12^{\circ}$, (b) $1 / 4^{\circ}$, (c) $1^{\circ}$, and (d) $1^{\circ}$ no-GM resolution versions of the OCCAM model, and (e) HadISST observations. All values are ${ }^{\circ} \mathrm{C}$ resulting from a one std dev increase in the SAM index. The $1 / 12^{\circ}$ and $1 / 4^{\circ}$ plots have been regrided to $1^{\circ}$ resolution to be consistent with the $1^{\circ}$ OCCAM and HadISST plots. Regressions significant at the 0.1 level or better are shown with diagonal shading. Also shown is the mean location of the Polar Front (black line). 

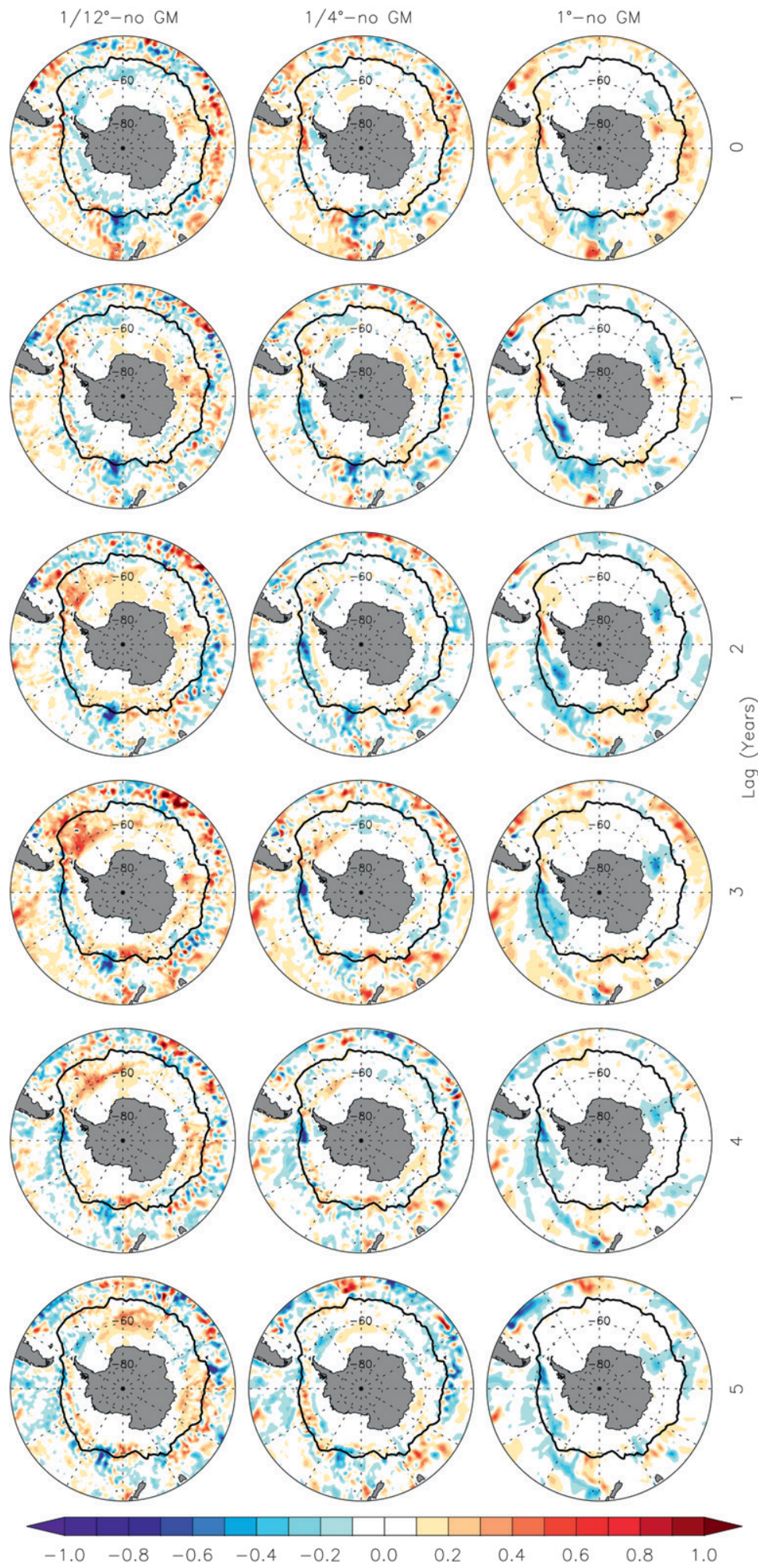

FIG. 4. Annual mean SST differences ( $\delta S S T$ ) regressed against the SAM index. $\delta$ SSTs have been calculated by subtracting the anomalies in the no-GM run from the corresponding anomalies in the $1 / 12^{\circ}, 1 / 4^{\circ}$, and $1^{\circ}$ runs of the OCCAM model (from left to right, respectively). Regressions are shown at varying lags ( $0-5 \mathrm{yr}$; from top to bottom). All values are ${ }^{\circ} \mathrm{C}$ resulting from a one std dev increase in the SAM index. Also shown is the mean location of the Polar Front (black line). 
temperature anomalies that are unrelated to eddy processes are removed. The resulting $\delta$ SSTs represent the component of the temperature anomalies related to eddy processes. Any eddy-driven warming in response to the SAM, as suggested by Hogg et al. (2008), will not be captured by the no-GM run and hence will be present in the $\delta$ SSTs. In the case of the $1 / 12^{\circ}$ run, the $\delta$ SSTs may result from explicitly resolved eddies. In contrast, the $\delta \mathrm{SST}$ in the $1^{\circ}$ run result from the eddy parameterization scheme. It is worth noting that increasing the model resolution has other effects in addition to improving the representation of eddies. These include differences in model bathymetry and in the structure and variability of boundary currents. However, we will show that the important differences in the temperature response, between fine- and coarse-resolution models, lag the SAM by $3 \mathrm{yr}$ and follow a delayed intensification of the mesoscale eddy field. It is unlikely that differences between the various resolution versions of the model, other than the ability (or inability) to explicitly resolve mesoscale eddies, would cause differences in the temperature response to the SAM with this distinct lag. Furthermore, the subsequent analyses show that the main differences in the temperature response to the SAM are located away from the seabed and eastern coasts. Therefore, factors such as improved model representation of bathymetry and western boundary currents are not likely to be important.

The regression patterns of the $\delta$ SSTs against the SAM index are shown in Fig. 4. The similarity between the regression maps in Fig. 3 would suggest that the $\delta$ SST regressions at zero lag would be small. Looking at the top panels in Fig. 4, this is generally the case. The largest differences are seen in the $1 / 12^{\circ}$ model to the north of the PF in the band of high EKE and SST variability previously identified (Fig. 1). It is perhaps unsurprising then that in these regions the regressions have no clear structure and are seen at all lags in the $1 / 12^{\circ}$ model. The high degree of variability in these regions means it is impossible to detect a robust eddy-driven temperature signal here. South of the PF, where EKE and SST variability are lower, this becomes less of a problem and the regression maps are less noisy.

At a lag of $3 \mathrm{yr}$, the regressions south of the $\mathrm{PF}$ are predominantly positive in the $1 / 12^{\circ}$ model, indicating that the ocean surface is warmer than in the no-GM run. A similar 3-yr-lagged warming is not apparent in either the $1 / 4^{\circ}$ or $1^{\circ}$ model. South of the PF the magnitude of this warming is larger than the magnitude of the initial eddy-independent response to the SAM (Fig. 3). The largest warming is found in the South Atlantic sector where the 3-yr-lag SST-SAM regressions in the $1 / 12^{\circ}$ run are up to $0.5^{\circ} \mathrm{C}$ higher than in the no-GM run. Most

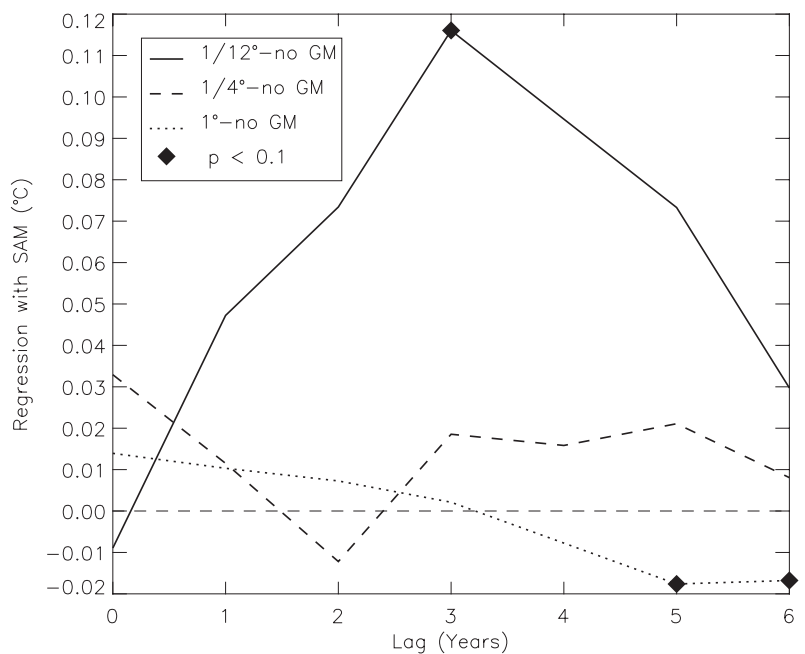

FIG. 5. Lagged regressions between annual mean SST differences ( $\delta$ SSTs) south of the Polar Front and the SAM index. SST anomalies have first been weighted by the cosine of latitude, and then averaged over the entire ocean between the Polar Front and $65^{\circ} \mathrm{S}$. Here, $\delta$ SSTs were calculated by subtracting the anomalies from the no-GM run from the corresponding anomalies in the $1 / 12^{\circ}$, $1 / 4^{\circ}$, and $1^{\circ}$ runs of the OCCAM model. Regressions significant at the 0.1 level or better are shown with diamonds.

of the regressions in Fig. 4 are not statistically significant at a gridpoint scale; however, they do show significance when spatially averaged. In Fig. 5 we show the same regressions, but averaged over the ocean south of the PF. It is clear that the $1 / 12^{\circ}$ model shows delayed eddy-driven warming that is not captured in the lower-resolution models. At a lag of $3 \mathrm{yr}$, the regression between $\delta \mathrm{SST}$ and the SAM is $0.11^{\circ} \mathrm{C}$ (per one standard deviation increase in the SAM index; $p=0.058)$. SSTs south of the $\mathrm{PF}$ appear to warm in the $1 / 12^{\circ}$ model, relative to the lower-resolution models, after a positive anomaly in the SAM. The eddy-driven warming is visible at lags of 1-6 $\mathrm{yr}$ and peaks at lag of $3 \mathrm{yr}$ (Fig. 5).

Figure 5 shows cooler SSTs in the $1^{\circ}$ model, relative to the no-GM run, 5-6 yr after a positive SAM anomaly. The 5- and 6-yr lag regressions between $\delta$ SST south of the PF and the SAM are significantly negative at the 0.1 level. However, the magnitudes of the regressions are very small (less than $0.02^{\circ} \mathrm{C}$ ) and a physical mechanism for this is not apparent. From the original regression maps (e.g., Fig. $4,1^{\circ}$ model at 5 -yr lag), we see that the largest contribution to the spatial average comes from a small patch of negative regressions slightly upstream of Drake Passage.

\section{Eddy-driven temperature changes at depth}

Thus far we have focused on SSTs because of their importance in driving the atmosphere; however, an 

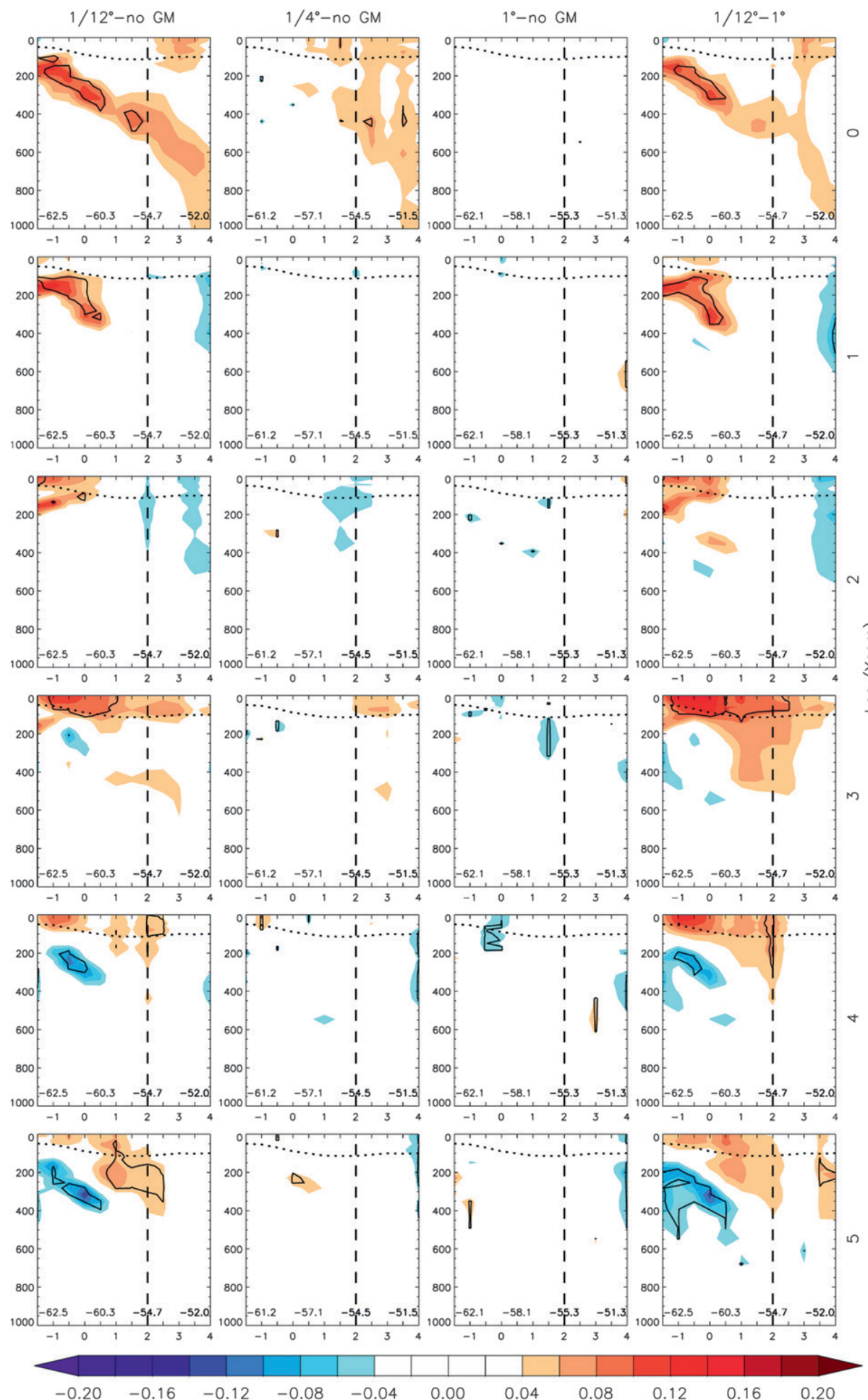

FIG. 6. Quasi-streamline mean, annual mean potential temperature differences ( $\delta \mathrm{PTs})$ regressed against the SAM index. $\delta$ PTs have been calculated by subtracting the anomalies in the no-GM run from the corresponding anomalies in the (left) $1 / 12^{\circ}$, (middle left) $1 / 4^{\circ}$, and (middle right) $1^{\circ}$ runs of the OCCAM model. (right) Additionally, $\delta \mathrm{PTs}$ were calculated by subtracting the anomalies from the $1^{\circ}$ run from the corresponding anomalies in the $1 / 12^{\circ}$ run. Regressions are shown along quasi streamlines (denoted by the corresponding temperature, ${ }^{\circ} \mathrm{C} ; x$ axes) for the top $1000-\mathrm{m}$ depth $(y$ axes) at (top to bottom) varying lags $(0-5 \mathrm{yr})$. The mean latitudes of selected quasi streamlines are provided. 
increase in eddy activity has the potential to raise temperatures throughout the water column. Mechanisms driving temperature changes in the middepth ocean are of particular interest because observations suggest that there has been warming at these depths over recent decades (Gille 2002, 2008). The ACC has large latitudinal variation; therefore, taking a simple zonal mean may average out important features, especially those resulting from transient eddies (Treguier et al. 2007). Instead, we have taken an average following the ACC pathway, using the time mean isotherms in the temperature minimum layer at $100-300-\mathrm{m}$ depth. These quasi streamlines are consistent with our chosen definition of the PF (based on Belkin and Gordon 1996) such that the $2^{\circ} \mathrm{C}$ quasi streamline corresponds to the mean PF. To examine temperature changes at depth we have calculated quasi-streamline mean potential temperature differences ( $\delta \mathrm{PTs})$ by subtracting the quasistreamline mean potential temperature anomalies in the no-GM run from the corresponding anomalies in the $1 / 12^{\circ}, 1 / 4^{\circ}$, and $1^{\circ}$ models.

The regressions of quasi-streamline mean $\delta \mathrm{PTs}$ against the SAM are shown in Fig. 6 for the upper 1000 $\mathrm{m}$ of the ocean. The warming south of the PF can clearly be identified in the regressions at lag of $3 \mathrm{yr}$ for the $1 / 12^{\circ}$ model. As with the surface warming this significant change is only evident at this resolution. The warming is surface intensified and confined to the mixed layer. Over most latitudes south of the PF, the regressions are significantly positive throughout the mixed layer at a lag of $3 \mathrm{yr}$. Warming of up to $0.1^{\circ} \mathrm{C}$ (per one standard deviation increase in the SAM index) can be seen to a depth of approximately $100 \mathrm{~m}$.

In addition to the near-surface warming at a lag of 3 $\mathrm{yr}$, the $1 / 12^{\circ}$ model displays apparent warming south of the PF at depths of 150-400 m, occurring at 0- and 1-yr lags. Given that the response of the eddy field to the SAM is lagged by $2-3$ yrs it seems unlikely that this warming is eddy driven. Instead, further examination revealed that this warming is most likely a consequence of heave. A positive anomaly in the SAM index causes enhanced upwelling at these latitudes $\left(55^{\circ}-65^{\circ} \mathrm{S}\right)$ to feed the anomalous Ekman divergence in the surface layers (Hall and Visbeck 2002; Sen Gupta and England 2006). In this region of the Southern Ocean, the mean temperature profile is characterized by colder water overlying warmer water (not shown). Upwelling raises the density surfaces and results in an apparent warming in the absence of water mass change (Bindoff and McDougall 1994). The magnitude of this warming is dependent on the strength of the upwelling and the vertical temperature gradient. All of the models are forced by the same wind stresses and would be expected to exhibit comparable upwelling. However, the mean vertical temperature gradient (between 150 and $400 \mathrm{~m}$ ) in the $1 / 12^{\circ}$ model is more pronounced (not shown), which likely explains why the warming resulting from heave is also more pronounced at this resolution.

One potential limitation of our method of calculating $\delta$ PT by subtracting the anomalies from the no-GM run is that any peculiarities in the no-GM run resulting from incomplete physics could appear in the subsequent $\delta$ PTs. Our earlier analyses have suggested that the eddy parameterization scheme is unable to capture the delayed temperature response to increased eddy activity. Assuming this, we recalculated $\delta \mathrm{PT}$ subtracting the anomalies from the $1^{\circ}$ run (with eddy parameterization) from the corresponding anomalies in the $1 / 12^{\circ}$ model (far right column in Fig. 6). The results from this analysis are largely consistent with those previously found. There is some evidence of the delayed warming seen in the $1 / 12^{\circ}$ model at $3-y r$ lag extending below the mixed layer to a depth of approximately $500 \mathrm{~m}$. However, the warming below the mixed layer is largely not statistically significant.

\section{Discussion}

This study has provided evidence that the Southern Ocean mesoscale eddy field intensifies (weakens) approximately $2-3 \mathrm{yr}$ after a positive (negative) anomaly in the SAM index, confirming results based on the quasigeostrophic model of Meredith and Hogg (2006). Strengthened westerlies during the positive phase of the SAM cause a northward Ekman transport, which acts to steepen the isopycnal slope across the ACC. This leads to baroclinic instability giving rise to eddies that act to flatten the isopycnal slopes. Meredith and Hogg (2006) show that the lag arises because the initial amplification of eddy activity is slow; however, as eddy activity increases, momentum is transferred from the upper layers to the lower layers where bottom topography steers the flow. These authors suggest that this steered flow is more baroclinically unstable, causing enhanced eddy

FIG. 6. (Continued). All values are ${ }^{\circ} \mathrm{C}$ resulting from a one std dev increase in the SAM index. Regressions significant at the 0.1 level or better are shown by the solid black contour. Also plotted are the mean mixed layer depth (dotted line) and the mean PF (dashed line). 
activity. This positive feedback gradually amplifies the eddy response and results in the EKE maximum lagging the wind forcing by $2-3 \mathrm{yr}$.

The initial SST response to a positive SAM anomaly is characterized by predominant cooling south of $45^{\circ} \mathrm{S}$ and warming to the north. This pattern (Fig. 3) is driven by a combination of modified Ekman flux and atmosphereocean heat fluxes that respond rapidly to a change in the SAM (Sen Gupta and England 2006; Verdy et al. 2006; Ciasto and Thompson 2008). By looking at monthly means we find that SSTs respond within 1 month to an anomaly in the SAM index (not shown). All resolutions of the model capture this response, including the noGM run, showing that eddies do not play an important role in the instantaneous response.

One to three years after a positive SAM anomaly, the ocean south of the $\mathrm{PF}$ warms in the $1 / 12^{\circ}$ model relative to the lower-resolution models (Fig. 5). The likely cause of this is an enhanced poleward heat flux associated with the intensification of mesoscale eddy activity. Eddies transport heat from the lower to higher latitudes across the fronts of the ACC (de Szoeke and Levine 1981; Lee et al. 2007). The maximum eddy-driven warming occurs approximately $3 \mathrm{yr}$ after the SAM anomaly, while the peak in EKE occurs after approximately 2 yr. This difference in lag arises because the warming is an integrated response to enhanced poleward heat flux over several years. Eddy activity is still intensified $3 \mathrm{yr}$ after the initial SAM anomaly (Fig. 2) and continues to warm the ocean south of the PF. Hogg et al. (2008) find a similar lag between the maximum eddy activity and the maximum warming response. In some regions of the Southern Ocean the lagged regressions of SST exceed $0.5^{\circ} \mathrm{C}$, showing a substantial temperature difference resulting from the presence of eddies. South of the PF, eddies are responsible for an area-averaged warming of approximately $0.11^{\circ} \mathrm{C}$ three years after a one standard deviation increase in the SAM index (in the $1 / 12^{\circ}$ model). For comparison, area averaging SSTs (Fig. 3a) south of the PF reveals an initial cooling of $0.06^{\circ} \mathrm{C}$. The results suggest that south of the PF the warming effects of increased mesoscale eddy activity at a lag of $3 \mathrm{yr}$ actually exceed the short-term cooling effects of modified atmosphere-ocean and Ekman heat fluxes. Furthermore, eddies are responsible for warming for several years after the initial atmospheric disturbance. Hogg et al. (2008) calculate that the total eddy heat flux response is greater than the Ekman transport heat flux by a factor of 2 .

The eddy-driven warming seen at the surface penetrates throughout the mixed layer with undiminished magnitude (Fig. 6). However, the warming appears to be surface intensified and disappears below the mixed layer. Observational and modeling studies have shown that EKE is strongly surface intensified (Stevens and Killworth 1992; Wilkin and Morrow 1994; Phillips and Rintoul 2000; Lenn et al. 2007), so it follows that the increase in EKE driven by the SAM is also likely to be greatest near the surface. In addition, the horizontal temperature gradient is greatest in the upper layers (not shown). For these reasons the resultant warming is most obvious in the top 100-200 m. For the first time in an eddyresolving model, we have shown the vertical structure of the delayed eddy-driven warming response to the SAM. The results here suggest that the response is strongly surface intensified and we find little evidence of eddy-driven warming below the mixed layer on interannual time scales.

With only $17 \mathrm{yr}$ of output we are unable to directly look at long-term trends. However, the results presented may have implications on decadal time scales in light of the observed trend toward the positive phase of the SAM. We have shown that the excitement of mesoscale eddies by the SAM causes warming in the near-surface Southern Ocean over interannual periods. Assuming that the same processes occur on decadal time scales, our results indicate a mechanism for Southern Ocean warming throughout the top $200 \mathrm{~m}$. The work of other authors, albeit through adaptations to the parameterization scheme rather than directly resolving the eddy field intensification, suggests that similar mechanisms do operate over decadal and centennial time scales (Fyfe et al. 2007). Indeed, in the longer term, the eddy heat flux may dominate the surface temperature response to the SAM (Hogg et al. 2008). Our results support recent model experiments, suggesting that an increase in mesoscale eddy activity has contributed to the observed Southern Ocean surface warming over recent decades (Fyfe et al. 2007; Hogg et al. 2008). Both observations and models suggest that middepth Southern Ocean temperatures have also risen over recent decades (Gille 2002, 2008; Fyfe 2006). We find little evidence to support an increase in eddy activity as a cause of observed temperature trends in the middepth ocean. However, we cannot rule out the possibility that changes in eddy activity may have a greater middepth temperature response over longer time scales.

By comparing coarse- with fine-resolution models we have demonstrated the impact of explicitly resolved eddies. All resolutions of the model successfully reproduce the observed short-term temperature response to the SAM driven by Ekman heat flux anomalies and atmosphere-ocean heat flux anomalies. However, the coarse-resolution models are unable to capture the delayed eddy-driven temperature response to the SAM. Only the $1 / 12^{\circ}$ model displays the warming associated with increased mesoscale eddy activity. Despite being 
able to resolve some eddies and showing a small but significant increase in eddy activity in response to the SAM, the $1 / 4^{\circ}$ model does not display any marked warming south of the PF. The weak EKE of the $1 / 4^{\circ}$ model may be partly attributed to the parameterization scheme, which competes with explicit eddies to flatten the isopycnal slopes. It seems to be necessary to resolve the smaller-scale eddies in order to capture the full temperature response. The parameterization scheme is unable to mimic the effects of changes in the eddy field on Southern Ocean temperatures. The results are discouraging for the climate modeling community because they suggest that low horizontal resolution models, such as those used in latest Intergovernmental Panel on Climate Change climate assessment (Solomon et al. 2007), are unable to capture aspects of the ocean temperature response to the SAM. This questions the ability of coarse-resolution climate models to accurately capture the impact of strengthening and poleward-shifting winds on the Southern Ocean. Hallberg and Gnanadesikan (2006) draw similar conclusions after finding marked differences in the response of the Southern Ocean overturning circulation to changes in wind stress, between low- and high-resolution models.

\section{Conclusions}

Observations and high-resolution model simulations both show that strengthened winds during the positive phase of the SAM lead to an increase in mesoscale eddy activity approximately 2-3 yr after the initial atmospheric disturbance. In the high-latitude Southern Ocean the initial temperature response to positive SAM is cooling driven by anomalous surface currents and anomalous atmosphere-ocean heat fluxes. In the longer term, the increase in mesoscale eddy activity causes an enhanced poleward heat flux, which acts to warm the highlatitude Southern Ocean. The warming is of greater magnitude and occurs for longer than the initial nearsurface cooling response. The eddy-driven warming signal is surface intensified and strongest within the mixed layer. Coarse-resolution models, in which mesoscale eddies are parameterized, are unable to capture this aspect of the temperature response to the SAM.

Acknowledgments. We thank Beverly de Cuevas and Andrew Coward of the OCCAM team at the National Oceanography Centre, Southampton, United Kingdom, for supplying the model output. Three anonymous reviewers provided useful suggestions to improve the paper. The satellite altimeter products were produced by Ssalto/Duacs and distributed by Aviso. The HadISST dataset was assembled by the Met Office Hadley Centre and obtained through the BADC. NCEP-NCAR reanalysis data were provided by the NOAA/OAR/ ESRL PSD, Boulder, Colorado.

\section{REFERENCES}

Alory, G., S. Wijffels, and G. Meyers, 2007: Observed temperature trends in the Indian Ocean over 1960-1999 and associated mechanisms. Geophys. Res. Lett., 34, L02606, doi:10.1029/ 2006GL028044.

Aoki, S., M. Yoritaka, and A. Masuyama, 2003: Multidecadal warming of subsurface temperature in the Indian sector of the Southern Ocean. J. Geophys. Res., 108, 8081, doi:10.1029/ 2000JC000307.

Arblaster, J. M., and G. A. Meehl, 2006: Contributions of external forcings to southern annular mode trends. J. Climate, 19, 2896-2905.

Belkin, I. M., and A. L. Gordon, 1996: Southern Ocean fronts from the Greenwich meridian to Tasmania. J. Geophys. Res., 101, 3675-3696.

Bindoff, N. L., and T. J. McDougall, 1994: Diagnosing climate change and ocean ventilation using hydrographic data. $J$. Phys. Oceanogr., 24, 1137-1152.

Bretherton, C. S., M. Widmann, V. P. Dymnikov, J. M. Wallace, and I. Blade, 1999: The effective number of spatial degrees of freedom of a time-varying field. J. Climate, 12, 1990-2009.

Cai, W., 2006: Antarctic ozone depletion causes an intensification of the Southern Ocean super-gyre circulation. Geophys. Res. Lett., 33, L03712, doi:10.1029/2005GL024911.

Chelton, D. B., R. A. de Szoeke, M. G. Schlax, K. El Naggar, and N. Siwertz, 1998: Geographical variability of the first baroclinic Rossby radius of deformation. J. Phys. Oceanogr., 28, 433-460.

Ciasto, L. M., and D. W. J. Thompson, 2008: Observations of largescale ocean-atmosphere interaction in the Southern Hemisphere. J. Climate, 21, 1244-1259.

Coward, A. C., and B. A. de Cuevas, 2005: The OCCAM 66 level model: Physics, initial conditions and external forcing. Southampton Oceanography Centre Internal Rep. 99, 21 pp.

de Szoeke, R. A., and M. D. Levine, 1981: The advective flux of heat by mean geostrophic motions in the Southern Ocean. Deep-Sea Res., 28, 1057-1085.

Ducet, N., P. Y. Le Traon, and G. Reverdin, 2000: Global highresolution mapping of ocean circulation from TOPEX/Poseidon and ERS-1 and -2. J. Geophys. Res., 105, 19 477-19 498.

Fyfe, J. C., 2006: Southern Ocean warming due to human influence. Geophys. Res. Lett., 33, L19701, doi:10.1029/2006GL027247.

, O. A. Saenko, K. Zickfeld, M. Eby, and A. J. Weaver, 2007: The role of poleward-intensifying winds on Southern Ocean warming. J. Climate, 20, 5391-5400.

Gent, P. R., and J. C. McWilliams, 1990: Isopycnal mixing in ocean models. J. Phys. Oceanogr., 20, 150-155.

Gille, S. T., 2002: Warming of the Southern Ocean since the 1950s. Science, 295, 1275-1277.

, 2008: Decadal-scale temperature trends in the Southern Hemisphere Ocean. J. Climate, 21, 4749-4765.

Gillett, N. P., and D. W. J. Thompson, 2003: Simulation of recent Southern Hemisphere climate change. Science, 302, 273-275.

Gouretski, V. V., and K. Jancke, 1996: A new hydrographic data set for the South Pacific: Synthesis of WOCE and historical data. WHP SAC Tech. Rep. 2, WOCE Rep. 143/96, 110 pp. 
Hall, A., and M. Visbeck, 2002: Synchronous variability in the Southern Hemisphere atmosphere, sea ice, and ocean resulting from the annular mode. J. Climate, 15, 3043-3057.

Hallberg, R., and A. Gnanadesikan, 2006: The role of eddies in determining the structure and response of the wind-driven Southern Hemisphere overturning: Results from the modeling eddies in the Southern Ocean project. J. Phys. Oceanogr., 36, 2232-2252.

Hogg, A. McC., M. P. Meredith, J. R. Blundell, and C. Wilson, 2008: Eddy heat flux in the Southern Ocean: Response to variable wind forcing. J. Climate, 21, 608-620.

Kalnay, E., and Coauthors, 1996: The NCEP/NCAR 40-Year Reanalysis Project. Bull. Amer. Meteor. Soc., 77, 437-471.

Large, W. G., J. C. McWilliams, and S. C. Doney, 1997: Sensitivity to surface forcing and boundary layer mixing in a global ocean model: Annual-mean climatology. J. Phys. Oceanogr., 27, 2418-2447.

Lee, M. M., A. J. George Nurser, A. C. Coward, and B. A. de Cuevas, 2007: Eddy advective and diffusive transports of heat and salt in the Southern Ocean. J. Phys. Oceanogr., 37, 1376-1393.

Lenn, Y.-D., T. K. Chereskin, J. Sprintall, and E. Firing, 2007: Mean jets, mesoscale variability and eddy momentum fluxes in the surface layer of the Antarctic Circumpolar Current in Drake Passage. J. Mar. Res., 65, 27-58.

Marshall, G. J., P. A. Stott, J. Turner, W. M. Connolley, J. C. King, and T. A. Lachlan-Cope, 2004: Causes of exceptional atmospheric circulation changes in the Southern Hemisphere. Geophys. Res. Lett., 31, L14205, doi:10.1029/2004GL019952.

Meredith, M. P., and A. M. Hogg, 2006: Circumpolar response of Southern Ocean eddy activity to changes in the Southern Annular Mode. Geophys. Res. Lett., 33, L16608, doi:10.1029/ 2006GL026499.

Oke, P. R., and M. H. England, 2004: Oceanic response to changes in the latitude of the Southern Hemisphere subpolar westerly winds. J. Climate, 17, 1040-1054.

Phillips, H. E., and S. R. Rintoul, 2000: Eddy variability and energetics from direct current measurements in the Antarctic
Circumpolar Current south of Australia. J. Phys. Oceanogr., 30, 3050-3076.

Rayner, N. A., D. E. Parker, E. B. Horton, C. K. Folland, L. V. Alexander, D. P. Rowell, E. C. Kent, and A. Kaplan, 2003: Global analyses of sea surface temperature, sea ice and night marine air temperature since the late nineteenth century. $J$. Geophys. Res., 108, 4407, doi:10.1029/2002JD002670.

Roscoe, H. K., and J. D. Haigh, 2007: Influences of ozone depletion, the solar cycle and the QBO on the Southern Annular Mode. Quart. J. Roy. Meteor. Soc., 133, 1855-1864.

Sen Gupta, A., and M. H. England, 2006: Coupled oceanatmosphere-ice response to variations in the Southern Annular Mode. J. Climate, 19, 4457-4486.

Solomon, S., D. Qin, M. Manning, M. Marquis, K. Averyt, M. M. B. Tignor, and H. LeRoy Miller, Eds., 2007: Climate Change 2007: The Physical Science Basis Cambridge University Press, $1009 \mathrm{pp}$.

Stevens, D. P., and P. D. Killworth, 1992: The distribution of kinetic energy in the Southern Ocean: A comparison between observations and an eddy resolving general circulation model. Philos. Trans. Roy. Soc. London, 338B, 251-257.

Thompson, D. W. J., and J. M. Wallace, 2000: Annular modes in the extratropical circulations. Part I: Month-to-month variability. J. Climate, 13, 1000-1016.

_ , and S. Solomon, 2002: Interpretation of recent Southern Hemisphere climate change. Science, 296, 895-899.

Treguier, A. M., M. H. England, S. R. Rintoul, G. Madec, J. Le Sommer, and J.-M. Molines, 2007: Southern Ocean overturning across streamlines in an eddying simulation of the Antarctic Circumpolar Current. Ocean Sci., 3, 491-507.

Verdy, A., J. Marshall, and A. Czaja, 2006: Sea surface temperature variability along the path of the Antarctic Circumpolar Current. J. Phys. Oceanogr., 36, 1317-1331.

Wilkin, J. L., and R. A. Morrow, 1994: Eddy kinetic energy and momentum flux in the Southern Ocean: Comparison of a global eddy-resolving model with altimeter, drifter, and current-meter data. J. Geophys. Res., 99, 7903-7916. 